\title{
Non-surgical treatment of lung cancer: personalised stereotactic ablative radiotherapy
}

\author{
Maverick WK Tsang *, Michael KM Kam, SF Leung, Anthony TC Chan
}

\section{A B S T R A C T}

Stereotactic ablative radiotherapy has emerged as a standard treatment for medically inoperable stage I non-small-cell lung cancer and selected cases of lung metastasis. Techniques to freeze or limit tumour movement during treatment and imageguided radiation delivery are integral to a successful stereotactic ablative treatment without overdose of surrounding normal structures. In this article, the practice in a local oncology institution will be used

This article was published on 26 Sep 2014 at www.hkmj.org. to illustrate the concept of personalised stereotactic ablative radiotherapy.
Hong Kong Med J 2014;20:529-36

DOI: $10.12809 / \mathrm{hkmj} 144269$

\author{
${ }^{1}$ MWK Tsang *, FRCR, FHKAM (Radiology) \\ MKM Kam, FRCR, FHKAM (Radiology) \\ 'SF Leung, MD, FHKAM (Radiology) \\ ${ }^{2}$ ATC Chan, MD, FRCP \\ Department of Clinical Oncology, Prince of Wales Hospital, Shatin, Hong \\ Kong \\ 2 State Key Laboratory in Oncology in South China, The Chinese \\ University of Hong Kong, Shatin, Hong Kong \\ * Corresponding author: wk_tsang@clo.cuhk.edu.hk
}

\section{Introduction}

Lung cancer is the second most common cancer and number one killer among all cancers in Hong Kong. ${ }^{1}$ Non-small-cell lung cancer (NSCLC) accounts for about $80 \%$ of all lung cancer cases. Surgery remains the mainstay of treatment for early-stage NSCLC. For patients who refuse or are medically unfit for surgery, stereotactic ablative radiotherapy (SABR) has emerged as a standard treatment. In the era of personalised medicine, SABR should be executed with techniques which are most suitable for the patient. In this article, the concepts of SABR, tumour motion control, and image-guided radiation delivery will be introduced. Then, using the Prince of Wales Hospital as an example, the approach to selecting the appropriate techniques for execution of personalised SABR will be explained.

\section{Stereotactic ablative radiotherapy}

Stereotactic ablative radiotherapy, also named as stereotactic body radiotherapy, is defined as "an external beam radiotherapy method used to very precisely deliver a high dose of radiation to an extracranial target within the body, using either a single dose or a small number of fractions". of SABR is to give a very high (ablative) radiation dose to kill all cancer cells within the target while avoiding radiation damage to the surrounding normal tissues. For lung SABR, a radiation dose of 10 to 20 Gray (Gy, a radiation dose unit) per treatment fraction is delivered for a total of 48 to 60 Gy in five or less fractions within 2 weeks.

\section{Indications for stereotactic ablative radiotherapy in lung cancer}

Stage I non-small-cell lung cancer: medically inoperable disease or patient refuses surgery

Nowadays, SABR is the gold-standard treatment for patients with stage I NSCLC who refuse surgical intervention or are medically unfit to undergo surgery (mostly due to poor pulmonary function). Prospective phase I/II studies document local control rate of over $90 \%$ with SABR, with overall survival approaching that of surgery (Table $1^{3-10}$ ). In Hong Kong, the reported 2-year local control and 2-year overall survival rates were $89 \%$ to $95 \%$ and $53 \%$ to $87 \%$, respectively. ${ }^{11-13}$ Generally, SABR is well tolerated, even by patients with poor pulmonary function. Guckenberger et $\mathrm{al}^{14}$ demonstrated that SABR had only very limited acute and chronic pulmonary toxicity even in patients with poor pulmonary function and there was no requirement of minimal pulmonary function for safe practice of SABR.

In view of the encouraging data on local control and mild toxicity of SABR for medically inoperable cases, the gold-standard role of surgery for operable stage I NSCLC is now being challenged. At least two retrospective studies have shown that survival of patients with operable stage I NSCLC treated with SABR paralleled that of lobectomy. ${ }^{15,16}$ Another two prospective phase 2 trials reported $76 \%$ to $84 \%$ 2-to-3-year overall survival rates for operable stage I disease after SABR, which compares favourably to surgical outcomes. ${ }^{3,7}$ Unfortunately, all phase 3 trials 


\section{非手術治療肺腫瘤：個人化的立體定向消融} 放射療法

曾偉光、甘冠明、梁承暉、陳德章

立體定向消融放射治療已成為醫治患有第一期非小細胞肺癌但不適合 做手術的病人及個別肺轉移個案的標準。凍結或限制腫瘤移動的技術 和圖像引導放射治療是進行成功的立體定向消融治療不可或缺的元 素, 以避免周邊正常組織接受過高的電療劑量。本文會以本地一所腫 瘤科醫院的臨床實踐説明個人化立體定向消融放射治療的概念。 comparing SABR with surgery in operable stage I NSCLC were terminated prematurely due to poor accrual. Thus, the race between SABR and surgery for the title of standard treatment for operable stage I NSCLC continues without a foreseeable end.

\section{Oligometastasis involving the lungs with controlled primary tumour}

Generally, oligometastasis is defined as one to five metastatic lesions besides the primary tumour. Evidence has emerged that patients with limited metastases can be cured by removal of all metastases. The reported 10- and 15-year survival rates of patients undergoing complete lung metastasectomy were $26 \%$ and $22 \%$, respectively. Patients with fewer metastases and longer disease-free interval fared even better. ${ }^{17}$ Prospective studies of limited lung metastases treated with SABR reported 2-year local control and 2-year survival rates of $89 \%$ to $96 \%$ and $39 \%$ to $84 \%$, respectively, which are not inferior to the surgical results. ${ }^{18-21}$

\section{Stereotactic ablative radiotherapy versus conventional radiotherapy}

The local control rate of stage I NSCLC after SABR is $\geq 90 \%$, in contrast to $50 \%$ rate with conventional radiotherapy. ${ }^{22-24}$ A clinical dose-response curve of human malignant lung tumours has been established. ${ }^{25}$ Thus, a high local tumour control can be achieved by delivering a high radiation dose. In lung cancer, however, the intrathoracic normal structures (normal lung tissues, spinal cord, brachial plexus, oesophagus, trachea and main bronchi, heart, great vessels, ribs and skin) close to the tumour may also receive a high radiation dose which may cause severe or even fatal treatment complications. It is this radiation damage of normal structures that limits the possible radiation dose to the lung tumour in conventional radiotherapy.

Stereotactic ablative radiotherapy is able to deliver a very high radiation dose to the target while sparing the surrounding normal tissues, thanks to its intrinsic physical advantage. On the other hand, many normal structures can tolerate a small volume of high-dose radiation without complications. Thus, we can deliver high-dose tumour radiation and yet limit volumes of the surrounding normal tissues exposed to high-dose radiation by reducing the size of the radiation field. In SABR, radiation field size reduction can be achieved through incorporation of techniques to limit tumour movement during radiotherapy (tumour motion management) and image-guided radiation delivery.

\section{Physical property}

Compared with conventional radiotherapy, SABR is able to create a very rapid dose fall-off at the

TABLE I. Results of prospective studies of stereotactic ablative radiotherapy for early-stage non-small-cell lung cancer ${ }^{3-10}$

\begin{tabular}{|c|c|c|c|c|}
\hline Study & No. of patients & Inclusion & Doses & Results \\
\hline Timmerman et al, ${ }^{3} 2013$ & 26 & T1-T3N0M0, operable & 18 Gy $x 3$ fractions & $\begin{array}{l}\text { 2-Year LC 92\% } \\
2 \text {-Year OS } 84 \%\end{array}$ \\
\hline Nagata et al, ${ }^{4} 2012$ & 100 & T1NOM0, inoperable* & 12 Gy $x 4$ fractions & 3 -Year OS 60\% \\
\hline Ricardi et al, ${ }^{5} 2010$ & 62 & T1-T2N0M0, inoperable & 15 Gy $\times 3$ fractions & $\begin{array}{l}3 \text {-Year LC 88\% } \\
3 \text {-Year OS 57\% }\end{array}$ \\
\hline Timmerman et $a l,{ }^{6} 2010$ & 55 & T1-T2N0M0, inoperable & 18 Gy $x 3$ fractions & $\begin{array}{l}3 \text {-Year LC 98\% } \\
3 \text {-Year OS 56\% }\end{array}$ \\
\hline Nagata et al, ${ }^{7} 2010$ & 64 & T1N0M0, operable & 12 Gy $x 4$ fractions & 3 -Year OS 76\% \\
\hline Fakiris et al, ${ }^{8} 2009$ & 70 & T1-T2N0M0, inoperable & 20 Gy (T1) - 22 Gy (T2) x 3 fractions & $\begin{array}{l}3 \text {-Year LC 88\% } \\
3 \text {-Year OS 43\% }\end{array}$ \\
\hline Baumann et al, ${ }^{9} 2009$ & 57 & T1-T2N0, inoperable & 15 Gy $\times 3$ fractions & $\begin{array}{l}3 \text {-Year LC 92\% } \\
\text { 3-Year OS 60\% }\end{array}$ \\
\hline Nagata et al, ${ }^{10} 2005$ & 45 & T1-T2NOM0, inoperable & 12 Gy $x 4$ fractions & 3-Year OS 83\% (T1) - 72\% (T2) \\
\hline
\end{tabular}

Abbreviations: $\mathrm{LC}=$ local control; OS = overall survival

* Inoperable means medically inoperable or patient refused surgery 
target normal tissue interface so that radiation can be precisely delivered to the target without damaging the surrounding normal tissues. This can be achieved by aligning the treatment field borders or multi-leaf collimators close to the planning target volume (PTV) borders (refer to the "Individualised radiation target volume" section below for definition of PTV) and by prescribing dose at the part of the radiation dose depth curve with a steep slope, ie $60 \%$ to $90 \%$ isodose line. Such rapid dose fall-off property of SABR can be further enhanced by adoption of intensity-modulated radiotherapy or volumetricmodulated arc therapy techniques which, in addition, can create a concave radiation dose distribution to further improve radiation dose conformity to the target.

\section{Tumour movement restriction during radiotherapy}

A lung tumour will move with respiration. In conventional radiotherapy, the radiation field is enlarged to encompass the tumour in all respiratory phases. In SABR, however, tumour movement during radiotherapy is restricted by various tumour motion management techniques. As a result, the radiation field can be smaller, thereby, limiting the amount of normal tissues exposed to a high radiation dose.

\section{Image-guided radiotherapy}

Even with proper tumour motion management, there will be residual tumour movement both during the same treatment fraction (intra-fraction) and between different fractions on different days (inter-fractions). Therefore, daily pretreatment verification of tumour position by various imageguided radiotherapy (IGRT) techniques is essential to avoid geographical tumour miss. Radiation field size reduction can only be realised with IGRT.

\section{Techniques to freeze or restrict movement of a lung tumour during stereotactic ablative radiotherapy}

\section{Active breathing control/voluntary inspiratory breath-hold}

Breath-holding SABR can be achieved actively by active breathing control $(A B C)$ or voluntarily by self-initiated breath-hold. The ABC apparatus is a modified spirometer consisting of two pairs of flow monitors and scissor valves to control inspiration and expiration, respectively. The operator activates $\mathrm{ABC}$ at a predefined lung volume by closing both valves to immobilise the breathing motion for 15 to 20 seconds. At the same time, radiation beam is switched on. Then, the patient is allowed to breathe freely until the next $\mathrm{ABC}$ activation. The cycle is repeated until complete delivery of a treatment fraction, which typically takes 30 minutes. Mostly,
$A B C$ will be activated in inspiration when lungs expand, resulting in less normal lung irradiation (Fig 1a). A study showed that ABC reduced normal lung V20 (volume of normal lung tissues receiving a dose $\geq 20 \mathrm{~Gy}$ ) by $34 \%$ compared with free breathing. ${ }^{26}$ There is a good reproducibility of lung tumour position under $\mathrm{ABC}$ both inter-fractionally and intra-fractionally, with mean tumour displacement in supero-inferior direction of $1.1 \mathrm{~mm}$ and $0.3 \mathrm{~mm}$, respectively. ${ }^{27,28}$ Voluntary inspiratory breath-hold technique is used in case a patient can hold his/her breath for at least 15 seconds but is unable to hold the mouthpiece of an $\mathrm{ABC}$ apparatus without air leakage.

\section{Respiratory gating}

Respiratory gating involves delivery of radiation only in certain phases of respiration. The gating window (respiratory phases at which radiation beam will be turned on) is usually selected at late expiratory

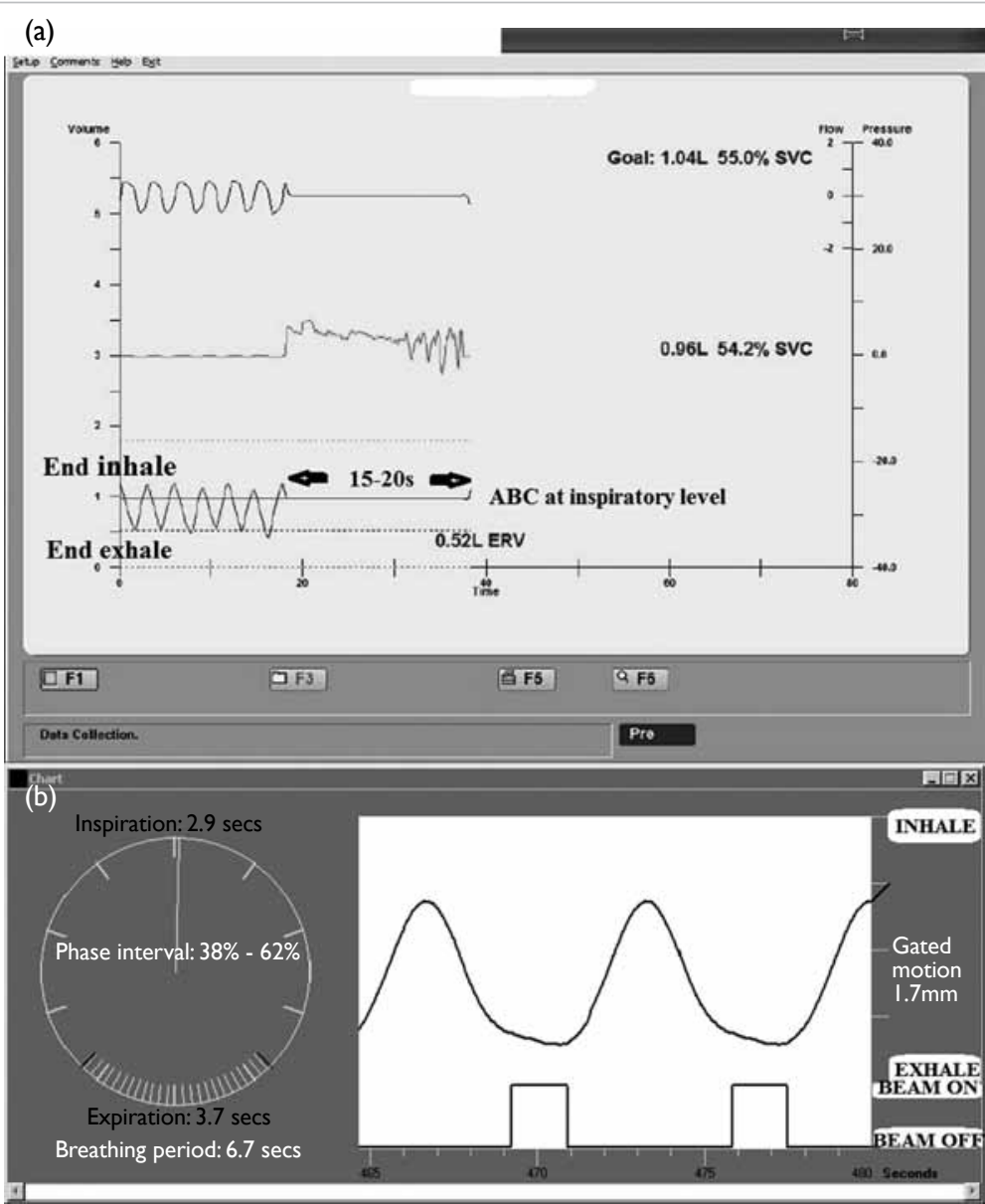

FIG I. Tumour motion management techniques

(a) Breathing waveform shows that active breathing control is activated at deep inspiratory level, and (b) Real-time Patient Management system respiratory gating, where radiation beam is on only at end of expiration

Abbreviations: $A B C=$ active breathing control; $E R V=$ expiratory reserve volume; SVC = slow vital capacity 
phases as a lung tumour stays for a longer period in the expiratory phase than in the inspiratory phase, resulting in a shorter treatment time. In addition, the tumour position will be more consistent and reproducible at end of expiration. A fourdimensional computed tomography (4D-CT; 4D means $3 \mathrm{D}+$ time) for radiotherapy planning purpose is done with the Real-time Patient Management (RPM) system (Varian Medical Systems, US), which consists of an infrared reflective block and an infrared tracking camera. The reflective block is placed on the anterior abdominal skin surface midway between the xiphisternum and umbilicus. The infrared camera tracks motion of the reflective block. The up-anddown breathing movement of the abdominal wall and thus position of the reflective block now reflects the respiratory phase during which a particular set of CT images are captured. As a result, positions of the tumour in various respiratory phases can be displayed on the 4D-CT images. A radiation field is designed according to the tumour positions at selected gating windows. Respiratory gating can be executed with either the RPM or the ExacTrac Adaptive Gating systems (Brainlab AG, Germany).

\section{Real-time Patient Management system}

During SABR, the infrared reflective block is placed on the patient's abdominal wall and serves as an external indicator to predict the tumour location. The infrared camera will track movements of the reflective block to turn the radiation beam on (at gating window) and off (Fig 1b).

\section{ExacTrac Adaptive Gating system}

Similar to the RPM system, ExacTrac has an optical infrared tracking system comprising several infrared reflective body markers (usually five to eight) and an infrared tracking camera mounted on the ceiling of the radiation treatment room (Fig $2 \mathrm{a}$ ). The radiation beam will be turned on only at a predefined gating window. The advantages and disadvantages of different tumour motion management techniques are tabulated in Table 2.

\section{Radiation delivery under image guidance}

Multiple studies have concluded that neither external indicators (infrared reflective block in the RPM system $^{29,30}$ ) nor internal indicators (diaphragm, ${ }^{31}$ bony anatomy such as vertebral bodies ${ }^{32,33}$ ) have a consistent correlation with tumour position over time. Therefore, direct visualisation of the lung tumour itself is required for accurate and precise radiation delivery. Image-guided radiotherapy is a procedure that uses various imaging techniques (eg X-ray and CT) to identify a tumour to guide the radiation beam during SABR treatment. It makes radiotherapy more accurate and causes less damage to healthy tissues.

Pretreatment verification of tumour position by a CT or X-ray imaging device mounted on a linear accelerator (Linac; a machine for generation and delivery of radiation beam) should be done daily for detection of inter-fractional tumour displacement, with necessary correction if there is significant tumour displacement from its planned position (Fig 3). Moreover, interval treatment verification with X-ray imaging during one treatment fraction is required for identification of intra-fractional tumour displacement.

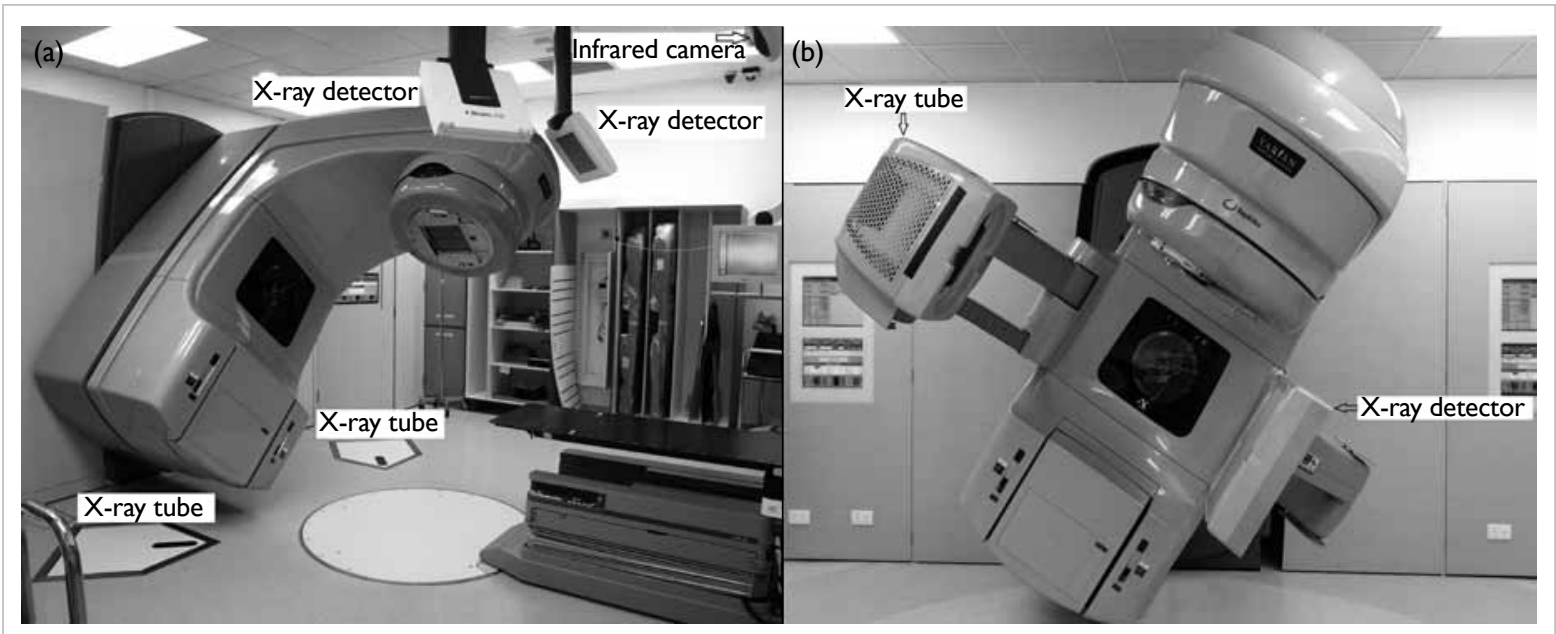

FIG 2. Image-guided radiotherapy facilities

(a) ExacTrac Adaptive Gating system. The two X-ray tubes are embedded on the room floor. The two amorphous silicon flat panel X-ray detectors, and the infrared tracking camera are mounted on the ceiling. (b) Onboard Imager.The X-ray tube and X-ray detector are mounted on the linear accelerator so that the $X$-ray tube-detector pair is always at $90^{\circ}$ to the treatment head of the linear accelerator 
TABLE 2. Comparison of different techniques

\begin{tabular}{|c|c|c|}
\hline Technique & Advantage & Disadvantage \\
\hline \multicolumn{3}{|c|}{ Tumour motion management technique } \\
\hline Breath-holding & $\begin{array}{l}\text { - Shorter treatment time } \\
\text { - Smallest radiation target volume }\end{array}$ & $\begin{array}{l}\text { - Not applicable for patients with compromised pulmonary } \\
\text { function } \\
\text { - Causes discomfort to patients }\end{array}$ \\
\hline Respiratory gating & $\begin{array}{l}\text { - Feasible even for patients with } \\
\text { compromised pulmonary function } \\
\text { - Comfortable for patients }\end{array}$ & $\begin{array}{l}\text { - Long treatment time } \\
\text { - Larger radiation target volume }\end{array}$ \\
\hline $\begin{array}{l}\text { Tumour Encompassing Targeting } \\
\text { ' } 3.5 \text { D' radiotherapy technique }\end{array}$ & $\begin{array}{l}\text { - Shortest treatment time } \\
\text { - Comfortable for patients }\end{array}$ & $\begin{array}{l}\text { - Largest radiation target volume } \\
\text { - Not applicable if tumour excursion }>1 \mathrm{~cm}\end{array}$ \\
\hline \multicolumn{3}{|c|}{ Image-guided radiotherapy technique } \\
\hline Onboard Imager & $\begin{array}{l}\text { - Useful for both breath-holding and } \\
\text { respiratory gating techniques } \\
\text { - Fluoroscopic mode available } \\
\text { - Fiducial marker implantation not necessary }\end{array}$ & $\begin{array}{l}\text { - Less accurate } \\
\text { - Uannot visualise small/obscure tumours } \\
\text { - Unable to verify tumour position when radiation beam is on }\end{array}$ \\
\hline Cone-beam CT & $\begin{array}{l}\text { - Accurate } \\
\text { - Can visualise the spatial relationship of } \\
\text { tumour and surrounding normal tissues } \\
\text { online } \\
\text { - Fiducial marker implantation not required }\end{array}$ & $\begin{array}{l}\text { - Takes a long time for image acquisition, therefore not } \\
\text { applicable for breath-holding technique } \\
\text { - Four-dimensional cone-beam CT unavailable in most } \\
\text { centres, therefore not applicable for respiratory gating } \\
\text { technique } \\
\text { - Unable to verify tumour position when radiation beam is on }\end{array}$ \\
\hline ExacTrac Adaptive Gating system & $\begin{array}{l}\text { - Can verify tumour position even when } \\
\text { radiation beam is on }\end{array}$ & $\begin{array}{l}\text { - For respiratory gating only } \\
\text { - Fiducial marker implantation necessary }\end{array}$ \\
\hline Fiducial marker guidance & - Accurate & $\begin{array}{l}\text { - Risk of pneumothorax which may require chest drain for air } \\
\text { drainage }\end{array}$ \\
\hline
\end{tabular}

Abbreviation: CT = computed tomography
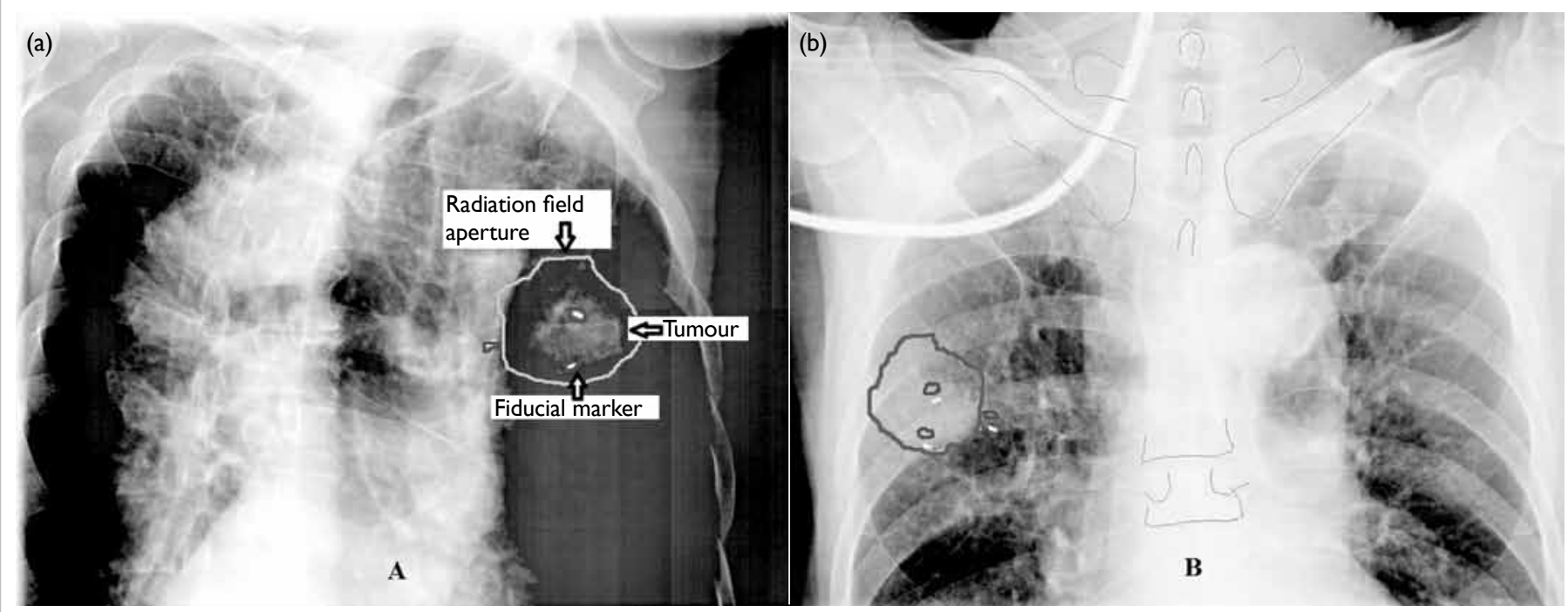

FIG 3. Pretreatment verification of tumour position. The small circles indicate the area where the fiducial marker is expected to stay during radiotherapy

(a) No displacement of the tumour. (b) Tumour displacement from its expected position, as indicated by displacement of the fiducial markers outside the small circles. The patient has to be repositioned for correction of tumour displacement before start of radiotherapy

\section{Onboard Imager}

Onboard Imager (OBI; Varian Medical Systems, US) is a high-resolution X-ray device mounted on the treatment head of a Linac to display real-time tumour location (Fig 2b). Radiographic images can be taken at the gating window for online (ie when a patient lies on treatment table of the Linac) verification of tumour position in RPM respiratory- gated radiotherapy. In $\mathrm{ABC}$ treatment, the tumour position under $A B C$ can also be verified online. It should be noted that X-ray images can be taken only when the radiation beam is turned off.

\section{Cone-beam computed tomography}

Cone-beam CT (CBCT) is a 3D mode of OBI, which is able to acquire and reconstruct $3 \mathrm{D}$ volumetric 
data in one rotation of treatment head of the Linac in 1 minute. Because of the long image acquisition time, CBCT is unsuitable for treatment verification if breath-holding or respiratory gating techniques are used. Rather, it is a useful and accurate tool for daily treatment verification of the Tumour Encompassing Targeting radiotherapy.

\section{ExacTrac Adaptive Gating}

The ExacTrac Adaptive Gating system has two components: the optical infrared tracking system for respiratory gating (mentioned above) and the stereoscopic X-ray imaging system for online detection and correction of tumour position shift. The stereoscopic X-ray imaging system consists of two X-ray tubes embedded in the Linac room floor and two amorphous silicon flat panel detectors mounted on the ceiling; the angle between the two

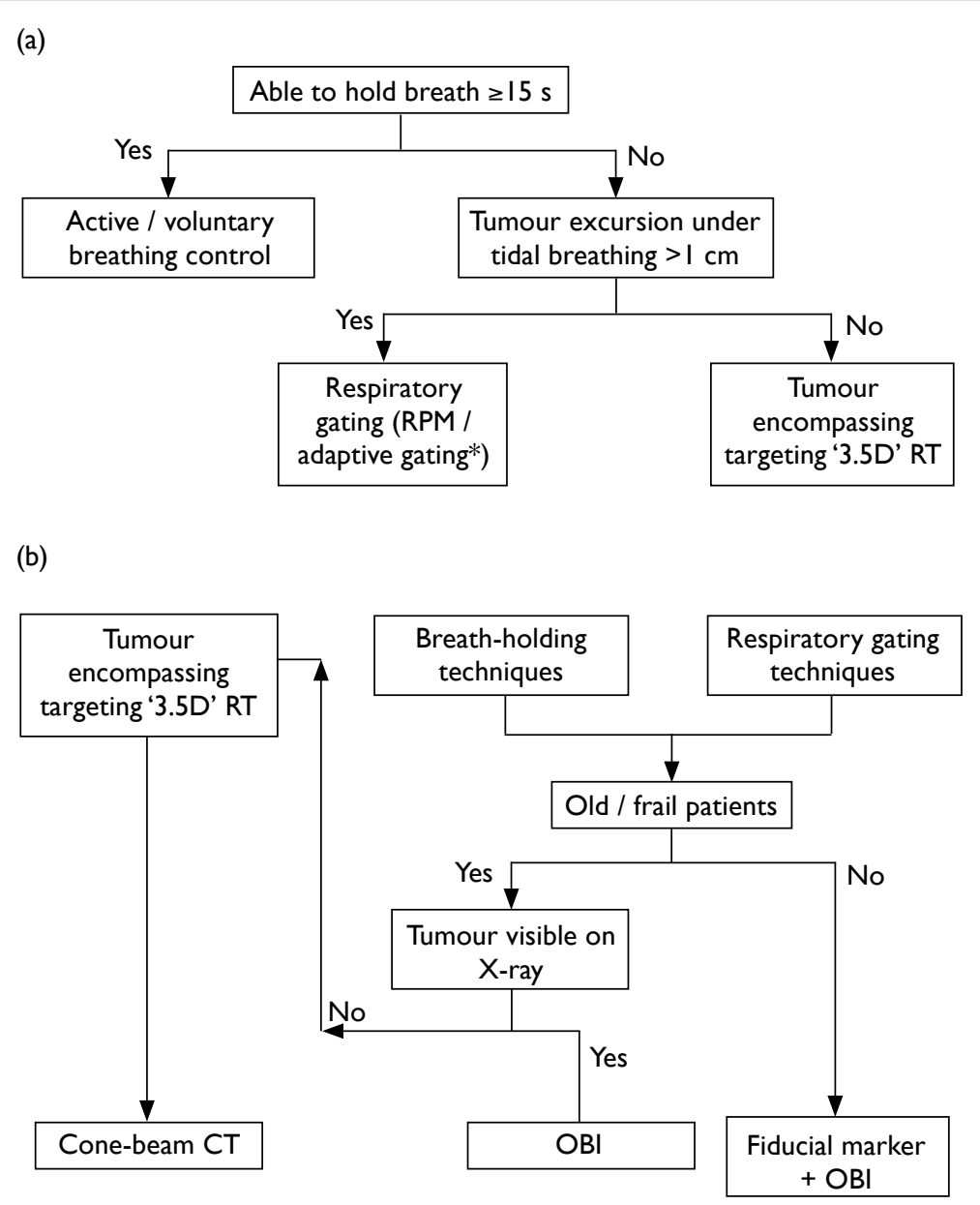

FIG 4. Flowcharts showing the approach to selecting appropriate tumour motion management and image-guided radiotherapy techniques for lung stereotactic ablative radiotherapy: (a) tumour motion management and (b) image-guided radiotherapy

Abbreviations: $\mathrm{CT}=$ computed tomography; $\mathrm{OBI}=$ Onboard Imager; $\mathrm{RPM}=$ Realtime Patient Management system; RT = radiotherapy

* Fiducial marker implantation necessary
X-ray tube-detector pairs is approximately $90^{\circ}$ (Fig 2a). Stereoscopic X-ray can be taken at the gating window for verification of tumour position. Its advantage over $\mathrm{OBI}$ is that periodic $\mathrm{X}$-ray acquisition at gating window is possible during both beam-on and beam-off periods. That means tumour displacement can be detected anytime during treatment, including during the beam-on period. Radiation beam can be turned off automatically if the tumour is displaced outside its allowed region. Table 2 compares the pros and cons of various IGRT techniques.

\section{Personalised stereotactic ablative radiotherapy adapted to patient's needs and limitations}

\section{Individualised tumour motion management}

The criteria for selection of an appropriate tumour motion management technique include (1) ability of the patient to tolerate inspiratory breath-hold for $\geq 15$ seconds, (2) extent of tumour movement at tidal breathing, and (3) selected IGRT technique (refer to the 'Individualised image-guided radiotherapy' section below for details).

Ideally, all patients should be treated under breath-holding condition as the lung tumour will be frozen and a minimal safety margin is required for creation of a radiation field. In practice, many lung cancer patients are elderly and smokers with compromised pulmonary function. These patients cannot hold the breath long enough for SABR treatment. For patients unsuitable for breath-holding techniques, a 4D-CT is done under tidal breathing to assess the magnitude of tumour movement. If it is $\leq 1 \mathrm{~cm}$, the Tumour Encompassing Targeting technique ('3.5D' radiotherapy) is used in which the radiation field will cover all possible tumour positions at any respiratory phase as shown on $4 \mathrm{D}-\mathrm{CT}$. For tumours with excessive $(>1 \mathrm{~cm})$ movement under tidal breathing, the respiratory gating technique should be utilised.

A flowchart showing the approach to selecting appropriate tumour motion management technique for lung SABR is shown in Figure 4a.

\section{Individualised image-guided radiotherapy}

An IGRT technique should be selected to match requirements of the selected tumour motion management technique and characteristics of the tumour (Fig 4b). A fiducial marker (a marker made of pure gold that can be visualised clearly on X-ray) can be implanted into or close to the tumour as an indicator of tumour location under OBI. There are various commercially available fiducial markers of different shapes and sizes, such as a cylindrical marker measuring $0.75 \mathrm{~mm}$ in diameter and $10 \mathrm{~mm}$ in length. Fiducial markers are implanted under CT guidance. In theory, all SABR treatments should be 
TABLE 3. Determination of target volumes in accordance with the selected tumour motion management and image-guided radiotherapy techniques

\begin{tabular}{|c|c|c|c|}
\hline & ABC & Tumour encompassing targeting & RPM respiratory gating / adaptive gating \\
\hline GTV & Tumour shown on $\mathrm{CT}$ done under $\mathrm{ABC}$ & $\begin{array}{l}\text { Summation of GTV throughout entire } \\
\text { 4D-CT data set }\end{array}$ & $\begin{array}{l}\text { Summation of GTV within gating window } \\
\text { (typically phases } 40 \%-60 \% \text { or } 30 \%-70 \% \text { ) }\end{array}$ \\
\hline CTV & $=\mathrm{GTV}$ & $=\mathrm{GTV}$ & $=\mathrm{GTV}$ \\
\hline ITV & $\mathrm{GTV}+3 \mathrm{~mm}$ & $\mathrm{GTV}+3 \mathrm{~mm}$ & $\mathrm{GTV}+5 \mathrm{~mm}$ \\
\hline PTV & \multicolumn{2}{|c|}{$\begin{array}{l}\text { - Fiducial marker / CBCT for setup } \\
\text { - OBI for setup }\end{array}$} & $\begin{array}{l}+3 \mathrm{~mm} \\
+5 \mathrm{~mm}\end{array}$ \\
\hline
\end{tabular}

Abbreviations: $\mathrm{ABC}=$ active breathing control; $\mathrm{CBCT}=$ cone-beam computed tomography; 4D-CT = 4-dimensional computed tomography; $\mathrm{CTV}=$ clinical target volume; GTV = gross tumour volume; ITV = internal target volume; OBI = Onboard Imager; PTV = planning target volume; RPM = Real-time Patient Management

executed either under fiducial markers guidance or with $\mathrm{CBCT}$ as these are the most accurate methods for pretreatment tumour position verification. In fact, CBCT is the IGRT technique of choice for '3.5D' radiotherapy. Nearly all patients cannot hold the breath long enough for performing CBCT, which typically takes a minute for $360^{\circ}$ acquisition of a full set of CT images. Furthermore, 4D-CBCT is unavailable in most oncology centres in Hong Kong. As a result, CBCT pretreatment verification is impractical for both breath-holding and respiratory gating techniques. On the other hand, fiducial marker implantation under $\mathrm{CT}$ guidance will result in significant pneumothorax necessitating insertion of a chest drain. Thus, it is not recommended in old and/or frail patients. Provided that the tumour can be visualised on X-ray, OBI alone can be used for pretreatment verification in such patients. Unfortunately, a lung tumour may not be visible on X-ray because of its small size or close proximity to the ribs, mediastinum, or heart. If a fiducial marker is not implanted and the tumour is invisible on OBI, neither breath-holding nor respiratory-gated SABR treatment is realistic. Instead, the ' $3.5 \mathrm{D}$ ' radiotherapy technique should be utilised with CBCT pretreatment verification.

\section{Individualised radiation target volume}

The International Commission on Radiation Units and Measurements Report 62 clearly defines various target volumes for radiation. ${ }^{34}$ Gross tumour volume (GTV) is the tumour mass shown on clinical examination or by imaging. Clinical target volume (CTV) encompasses the subclinical microscopic disease around GTV. In SABR, the tissue immediately around GTV will receive a dose high enough to eradicate all possible microscopic disease. Therefore, CTV margin is not required in most of the cases, ie GTV $=$ CTV. To compensate for possible inter-fractional and intra-fractional tumour movement, a further margin (internal margin [IM]) is added to CTV to create the internal target volume (ITV). As 4D-CT scan for radiotherapy planning only delineates the snapshot tumour movement at the time of scanning, an IM is still required to allow for residual tumour movement. A final setup margin $(\mathrm{SM})$ for all uncertainties in patientradiation beam positioning during radiotherapy treatment is added to ITV to become the final PTV. The required IM and SM depend on the selected tumour motion management and IGRT techniques. As the breathing pattern of patients may change significantly both within one treatment and between different treatment sessions, a larger IM is indicated for respiratory gating techniques. Compared with fiducial markers and $\mathrm{CBCT}, \mathrm{OBI}$ is less accurate for determination of tumour position during treatment, thereby, requiring a larger SM (Table 3).

\section{Conclusion}

Stereotactic ablative radiotherapy is the standard treatment for medically inoperable stage I NSCLC. Phase 3 trials are eagerly awaited to settle the debate on superiority of SABR or surgery in the treatment of operable stage I disease. Various tumour motion management and IGRT techniques are available for effective execution of SABR. Personalised SABR should be offered to suit each patient's needs and limitations.

\section{References}

1. Hong Kong Cancer Registry. Available from: http://www3. ha.org.hk/cancereg/. Accessed Jun 2014.

2. Practice guideline for the performance of stereotactic body radiation therapy. Reston VA: American College of Radiology (ACR); 2009: 8.

3. Timmerman RD, Paulus R, Pass HI, et al. RTOG 0618: Stereotactic body radiation therapy (SBRT) to treat operable early-stage lung cancer patients [abstract]. J Clin Oncol 2013;31(Suppl):abstract 7523.

4. Nagata Y, Hiraoka M, Shibata T, et al. Stereotactic body radiation therapy for T1N0M0 non-small cell lung cancer: first report for inoperable population of a phase II trial by Japan Clinical Oncology Group (JCOG 0403). Int J Radiat Oncol Biol Phys 2012;84(Suppl):S46.

5. Ricardi U, Filippi AR, Guarneri A, et al. Stereotactic body radiation therapy for early stage non-small cell lung cancer: 
results of a prospective trial. Lung Cancer 2010;68:72-7.

6. Timmerman R, Paulus R, Galvin J, et al. Stereotactic body radiation therapy for inoperable early stage lung cancer. JAMA 2010;303:1070-6.

7. Nagata Y, Hiraoka M, Shibata T, et al. A phase II trial of stereotactic body radiation therapy for operable T1N0M0 non-small cell lung cancer: Japan Clinical Oncology Group (JCOG0403). Int J Radiat Oncol Biol Phys 2010;78(Suppl):S27-8.

8. Fakiris AJ, McGarry RC, Yiannoutsos CT, et al. Stereotactic body radiation therapy for early-stage non-small-cell lung carcinoma: four-year results of a prospective phase II study. Int J Radiat Oncol Biol Phys 2009;75:677-82.

9. Baumann P, Nyman J, Hoyer $M$, et al. Outcome in a prospective phase II trial of medically inoperable stage I non-small-cell lung cancer patients treated with stereotactic body radiotherapy. J Clin Oncol 2009;27:32906.

10. Nagata Y, Takayama K, Matsuo Y, et al. Clinical outcomes of a phase I/II study of $48 \mathrm{~Gy}$ of stereotactic body radiotherapy in 4 fractions for primary lung cancer using a stereotactic body frame. Int J Radiat Oncol Biol Phys 2005;63:1427-31.

11. Chan OS, Yeung RM, Hung AW, et al. Stereotactic ablative radiotherapy for medically inoperable early stage lung cancer: early outcomes. Hong Kong Med J 2012;8:412-8.

12. Tsang WK. Stereotactic and respiratory-gated radiotherapy: local experience. Proceedings of the 4th Asia Pacific Perspectives in Lung Cancer 2010; 2010 Sep 3-4. Hong Kong.

13. Ng AW, Tung SY, Wong VY. Hypofractionated stereotactic radiotherapy for medically inoperable stage I non-small cell lung cancer-report on clinical outcome and dose to critical organs. Radiother Oncol 2008;87:24-8.

14. Guckenberger M, Kestin LL, Hope AJ, et al. Is there a lower limit of pretreatment pulmonary function for safe and effective stereotactic body radiotherapy for early-stage non-small cell lung cancer? J Thorac Oncol 2012;7:542-51.

15. Shirvani SM, Jiang J, Chang JY, et al. Comparative effectiveness of 5 treatment strategies for early-stage nonsmall cell lung cancer in the elderly. Int J Radiat Oncol Biol Phys 2012;84:1060-70.

16. Onishi H, Shirato H, Nagata Y, et al. Stereotactic body radiotherapy (SBRT) for operable stage I non-small-cell lung cancer: can SBRT be comparable to surgery? Int J Radiat Oncol Biol Phys 2011;81:1352-8.

17. Long-term results of lung metastasectomy: prognostic analyses based on 5206 cases. The International Registry of Lung Metastases. J Thorac Cardiovasc Surg 1997;113:3749.

18. Ricardi U, Filippi AR, Guarneri A, et al. Stereotactic body radiation therapy for lung metastases. Lung Cancer 2012;75:77-81.

19. Rusthoven KE, Kavanagh BD, Burri SH, et al. Multiinstitutional phase I/II trial of stereotactic body radiation therapy for lung metastases. J Clin Oncol 2009;27:1579-84.

20. Norihisa Y, Nagata Y, Takayama K, et al. Stereotactic body radiotherapy for oligometastatic lung tumors. Int J Radiat
Oncol Biol Phys 2008;72:398-403.

21. Yoon SM, Choi EK, Lee SW, et al. Clinical results of stereotactic body frame based fractionated radiation therapy for primary or metastatic thoracic tumors. Acta Oncol 2006;45:1108-14.

22. Haffty BG, Goldberg NB, Gerstley J, Fischer DB, Peschel RE. Results of radical radiation therapy in clinical stage I, technically operable non-small cell lung cancer. Int J Radiat Oncol Biol Phys 1988;15:69-73.

23. Kaskowitz L, Graham MV, Emami B, Halverson KJ, Rush C. Radiation therapy alone for stage I non-small cell lung cancer. Int J Radiat Oncol Biol Phys 1993;27:517-23.

24. Krol AD, Aussems P, Noordijk EM, Hermans J, Leer JW. Local irradiation alone for peripheral stage I lung cancer: could we omit the elective regional nodal irradiation? Int J Radiat Oncol Biol Phys 1996;34:297-302.

25. Fletcher GH. Clinical dose-response curves of human malignant epithelial tumours. Br J Radiol 1973;46:1-12.

26. Barnes EA, Murray BR, Robinson DM, Underwood LJ, Hanson J, Roa WH. Dosimetric evaluation of lung tumor immobilization using breath hold at deep inspiration. Int J Radiat Oncol Biol Phys 2001;50:1091-8.

27. Kashani R, Balter JM, Hayman JA, Henning GT, van Herk M. Short-term and long-term reproducibility of lung tumor position using active breathing control (ABC). Int J Radiat Oncol Biol Phys 2006;65:1553-9.

28. Cheung PC, Sixel KE, Tirona R, Ung YC. Reproducibility of lung tumor position and reduction of lung mass within the planning target volume using active breathing control (ABC). Int J Radiat Oncol Biol Phys 2003;57:1437-42.

29. Koch N, Liu HH, Starkschall G, et al. Evaluation of internal lung motion for respiratory-gated radiotherapy using MRI: Part I-correlating internal lung motion with skin fiducial motion. Int J Radiat Oncol Biol Phys 2004;60:1459-72.

30. Berbeco RI, Nishioka S, Shirato H, Chen GT, Jiang SB. Residual motion of lung tumours in gated radiotherapy with external respiratory surrogates. Phys Med Biol 2005;50:3655-67.

31. Wang J, Liang J, Hugo G, et al. Distance between thoracic tumor position and diaphragm position during the course of radiotherapy: does it remain constant? Int J Radiat Oncol Biol Phys 2005;63:S524.

32. Guckenberger M, Meyer J, Wilbert J, et al. Cone-beam CT based image-guidance for extracranial stereotactic radiotherapy of intrapulmonary tumors. Acta Oncol 2006;45:897-906.

33. Purdie TG, Bissonnette JP, Franks K, et al. Cone-beam computed tomography for on-line image guidance of lung stereotactic radiotherapy: localization, verification, and interfraction tumor position. Int J Radiat Oncol Biol Phys 2007;68:243-52.

34. Prescribing, recording and reporting photon beam therapy (Report 62 by International Commission on Radiation Units and Measurements). Available from: http://www. icru.org/home/reports/prescribing-recording-andreporting-photon-beam-therapy-report-62. Accessed Sep 2014. 